\title{
Evaluation of the Levels of Evidence in Medical Articles in Korea
}

\author{
Yang Ju Tak ${ }^{1}$, Gilwon Kang ${ }^{2}$ and Youngsung Lee ${ }^{3}$ \\ ${ }^{1}$ Department of Paramedic Science, Korea National University of Transportation, 61 \\ Daehak-ro, Jeungpyeong, Chungbuk 368-701, Korea \\ ${ }^{2,}{ }^{3}$ Department of Health Informatics \& Management, Chungbuk National \\ University College of Medicine, 52 Naesudong-ro, Heungduk-gu, Cheongju, \\ Chungbuk 361-763, Korea \\ 1yjtak@ut.ac.kr, ${ }^{2}$ gilwon67@chungbuk.ac.kr
}

\begin{abstract}
The purpose of this study was to investigate the quality of medical research articles published in Korea. To evaluate the quality of medical research articles published in Korea, we compared levels of evidence in medical articles published in Korea and abroad. We chose 2 medical journals in Korea and abroad respectively which representing 15 clinical areas and reviewed all articles published in 1996 and 2008. We used the guidelines of Oxford Centre for Evidence-based Medicine (CEBM) for the quantitative evaluation and classified the levels of evidence in all articles. The majority of medical articles both in Korean and nonKorean medical journals were case-control study and next common were case studies. Whereas randomized controlled trials (RCTs), cohort studies, and systemic reviews were very rare. However, non-Korean articles had higher levels of evidence than did Korean ones, and this difference was statistically significant. In conclusion, although the quality of medical research articles in Korea improved, we were able to detect a gap in the levels of evidence contained in medical articles published in Korea and outside Korea.
\end{abstract}

Keywords: evidence-based medicine, level of evidence, quality of medical article

\section{Introduction}

The notion of evidence-based medicine, first introduced by David Sackett and Brian Haynes of McMaster University in Canada, was initially used in clinical decisions or treatment guidelines [1]. However, use of the concept has been extended to overall medical healthcare and now is applied even in the area of health policy [2, 3]. The most important requirement of evidence-based medicine is to gather and integrate all medical research results to reach overall conclusions. This process is called a systematic review, and the strength of the scientific evidence or recommendations contained in each article included in the review depends on the quality of that article [4]. The concept of "levels of evidence" was introduced to quantitatively evaluate the quality of each article. The Centre for Evidence-Based Medicine (CEBM) in Oxford, England developed widely employed criteria for levels of evidence [5]. According to these guidelines, the results of each systematic review are divided into five levels based on quality. One major distinction involves homogeneous, randomized controlled trials (RCTs) versus case reports or expert opinions.

In Korea, evidence-based medicine has also been introduced to a variety of medical fields, used clinically, and adopted in education. Indeed, it is frequently used for health insurance and assessment services, which adopted evidence-based medicine as a way to evaluate the 
appropriateness and efficiency of health technology. In addition to the clinical field, evidencebased medicine has spread to nursing, public health administration, Oriental medicine, and pharmacy. However, it has not yet become part of the overall decision-making process. During the 1990s, the governments of some countries compiled clinical treatment guidelines, whereas Korea recognized the need for guidelines in the 2000s and began to conduct relevant research at that time. In 2008, the Clinical Treatment Guideline Information Center, which later launched a program to prepare guidelines on asthma and depression, was established. Although the Center has been making efforts to update the guidelines, evidence-based medicine has not yet been accepted in all fields of medicine.

Additionally, studies on the effectiveness and safety of various remedies for diverse diseases [6] and on the degree to which evidence-based medicine has spread to specific clinical fields have been conducted. Research conducted from an evidence-based perspective assessing the quality of medical research has also been performed. Studies analyzing the levels of evidence underpinning specific research results and analyses of studies evaluating the quality of research are in progress. Furthermore, several analyses of the quality-evaluation research conducted in regard to some Korean journals have been published, but the overall quality of Korean articles and the qualitative differences between Korean and non-Korean articles have not been investigated. In this study, we compared the levels of evidence in Korean and non-Korean articles to identify differences in this regard.

\section{Methods}

\subsection{Selecting Representative Journals}

We selected 15 clinical areas (internal medicine, pediatrics, psychiatry, family medicine, general surgery, obstetrics and gynecology, orthopedics, thoracic surgery, neurosurgery, ophthalmology, otolaryngology, urology, dermatology, anesthesiology, and radiology) and asked two specialists in each field to choose one typical Korean and non-Korean journal. When the specialists did not agree or more than two journals were recommended, we selected the journal with the highest impact factor (Table 1).

Table 1. Representative Journals

\begin{tabular}{|c|c|c|}
\hline & Korean Journals & Foreign Journals \\
\hline Internal Medicine & Korean Journal of Medicine & Annals of Internal Medicine \\
\hline Pediatrics & $\begin{array}{l}\text { Journal of the Korean Pediatric } \\
\text { Society }\end{array}$ & Pediatrics \\
\hline Surgery & $\begin{array}{l}\text { Journal of the Korean Surgical } \\
\text { Society }\end{array}$ & BJS (British Journal of Surgery) \\
\hline Obstetrics\& Gynecology & $\begin{array}{l}\text { Korean Journal of Obstetrics \& } \\
\text { Gynecology }\end{array}$ & $\begin{array}{l}\text { American Journal of Obstetrics } \\
\text { and Gynecology }\end{array}$ \\
\hline Orthopedics & $\begin{array}{l}\text { Journal of the Korean Orthopedic } \\
\text { Association }\end{array}$ & $\begin{array}{l}\text { JBJS (Journal of Bone and Joint } \\
\text { Surgery)American edition }\end{array}$ \\
\hline Cardiovascular Surgery & $\begin{array}{l}\text { Korean Journal of Thoracic and } \\
\text { Cardiovascular Surgery }\end{array}$ & The Annals of Thoracic Surgery \\
\hline Neurosurgery & $\begin{array}{l}\text { Journal of the Korean Neurosurgical } \\
\text { Society }\end{array}$ & JNS (Journal of Neurosurgery) \\
\hline Ophthalmology & Journal of the Korean & Ophthalmology \\
\hline
\end{tabular}




\begin{tabular}{l|l|l} 
Otolaryngology & $\begin{array}{l}\text { Ophthalmological Society } \\
\text { Korean Journal of Otolaryngology } \\
\text {-Head and Neck Surgery } \\
\text { Korean Journal of Urology } \\
\text { Journal of the Korean } \\
\text { Neuropsychiatric Association }\end{array}$ & $\begin{array}{l}\text { Laryngoscope } \\
\text { Journal of Urology } \\
\text { American Journal of Psychiatry } \\
\text { Psychiatry }\end{array}$ \\
$\begin{array}{ll}\text { Korean Journal of Dermatology } \\
\text { Dermatology } \\
\text { Radiology } \\
\text { Anesthesiology }\end{array}$ & $\begin{array}{l}\text { Korean Journal of Radiology } \\
\text { Kadiology }\end{array}$ \\
Kamily Medicine & $\begin{array}{l}\text { Journal of the Korean Academy } \\
\text { Family Medicine }\end{array}$ \\
\hline \hline
\end{tabular}

\subsubsection{Searching Articles and Extracting Objects for Analysis}

We extracted all Korean articles published in 1996 and 2008 using the Korean medical database (KMbase) of the Medical Research Information Center (MedRIC). For non-Korean articles, we extracted all articles published in 1996 and 2008 using Medline, the US National Library of Medicine's premier bibliographic database. Because many more non- Korean than Korean articles were published, we randomly chose the same number of Korean and nonKorean articles.

\subsection{Classification of Level of Evidence}

We modified the widely-used 2009 criteria for evidence-based evaluation issued by the Oxford Centre for Evidence-Based Medicine (CEBM). We evaluated articles based on abstracts and then used the entire article when the abstract was not sufficient.

\subsection{Data Analysis}

\subsubsection{Comparing Levels of Evidence by Nationality, Year, and Field}

We classified and compared the levels of evidence in articles published in Korean versus non-Korean journals, in 1996 versus in 2008, and across different fields. We also assessed statistical significance using the chi-square test for differences in the levels of evidence in Korean versus non-Korean journals by year. We replaced the chi-square test with Fisher's exact test in cases with inappropriate sample sizes. We used SPSS software (ver. 12.0 Korean) for all analyses.

\subsubsection{Comparing Levels of Evidence by Multiple Logistic Regression}

To integrally evaluate the levels of evidence in Korean versus non-Korean articles, we divided the articles into two groups according to whether their level of evidence was high (1a, $1 \mathrm{~b}, 2 \mathrm{a}, 2 \mathrm{~b})$ or low $(3 \mathrm{a}, 3 \mathrm{~b}, 4,5)$. We compared the levels of evidence of these two groups using multivariate logistic analysis. Explanatory variables were nationality (Korean versus non-Korean), year, and clinical area.

\subsubsection{Estimating Evidentiary Levels of Korean Articles}

We integrated all the evidentiary levels for each journal into one score to evaluate the overall evidentiary levels of Korean articles. As the number of articles published in each 
clinical field differed, however, we also considered the weight of each clinical field and determine a weighted average. The weight assigned to articles in each clinical area was based on a 2007 classification of domestic articles published by Jang [7]. This study classified all medical articles published in Korea in 2007 according to medical field and analyzed the number and rate of articles in each field (Table 2).

Table 2. Number of Articles in each Clinical Area in Korea

\begin{tabular}{l|ll}
\hline \hline & Total & Ratio \\
\hline Internal Medicine & 2,191 & $21.7 \%$ \\
Pediatrics & 562 & $5.6 \%$ \\
Surgery & 603 & $6.0 \%$ \\
Obstetrics \&Gynecology & 511 & $5.0 \%$ \\
Orthopedics & 632 & $6.2 \%$ \\
Cardiovascular Surgery & 161 & $1.6 \%$ \\
Neurosurgery & 335 & $3.3 \%$ \\
Ophthalmology & 503 & $5.0 \%$ \\
Otolaryngology & 577 & $5.7 \%$ \\
Urology & 372 & $3.7 \%$ \\
Psychiatry & 565 & $5.6 \%$ \\
Dermatology & 455 & $4.5 \%$ \\
Radiology & 402 & $4.0 \%$ \\
Anesthesiology & 464 & $4.6 \%$ \\
Family Medicine & 329 & $3.3 \%$ \\
Other & 1,229 & $12.1 \%$ \\
\hline \hline
\end{tabular}

\section{Results}

\subsection{Comparison of Levels of Evidence by Year}

\subsubsection{6}

In 1996, more articles with high levels of evidence (1a, 1b, 2a, 3a) were published abroad, and more articles with low levels of evidence ( $3 \mathrm{~b}$ and 4$)$ were published in Korea. This difference reached statistical significance ( $p<0.05$; Table 3$)$. 


\subsubsection{8}

In 2008, more articles with high levels of evidence (1a, 1b, 2a, 3a) were published abroad, and more articles with low levels of evidence ( $3 b$ and 4$)$ were published in Korea. Once again, this difference reached statistical significance $(p<0.05$; Table 3$)$.

\subsection{Comparison of Levels of Evidence by Nationality}

\subsubsection{Korean Journals}

No systematic reviews using data from randomized clinical trials (RCTs) were performed in 1996, and only two such reviews were performed in 2008. On the other hand, the number of reported RCTs almost doubled from 1996 to 2008, reflecting a statistically significant difference $(p<0.05)$. In 1996, case-control studies accounted for almost two-thirds of all articles reviewed, but this figure decreased by half in 2008, a change that reached statistical significance $(p<0.05)$. In 1996, two-thirds of all reports were case-control studies. However, the number of case-control studies decreased as the number of RCTs and case studies increased (Table 3).

\subsubsection{Non-Korean journals}

Systematic reviews of RCTs accounted for only $0.27 \%$ of the total in 1996 , but this figure almost quadrupled, to $1.36 \%$, in $2008(p<0.05)$. The number of case-control studies did not significantly change, but the number of systematic reviews plus cohort studies and casecontrol studies tripled. Additionally, the number of systematic reviews of cohort studies increased by a factor of $10(p<0.05)$. However, case-control studies accounted for the largest proportion of articles in non-Korean journals in both 1996 and 2008 (Table 3).

Table 3. Levels of Evidence in Korean and non-Korean Articles by Year

\begin{tabular}{|c|c|c|c|c|c|c|c|c|c|c|}
\hline & & $1 \mathrm{a}$ & $1 \mathrm{~b}$ & $2 \mathrm{a}$ & $2 b$ & $3 a$ & $3 b$ & 4 & 5 & Total \\
\hline Korea & $\begin{array}{l}1996 \\
2008\end{array}$ & $\begin{array}{l}0 \\
(0.00) \\
2 \\
(0.07)\end{array}$ & $\begin{array}{l}42 \\
(1.14) \\
84 \\
(2.87)\end{array}$ & $\begin{array}{l}0 \\
(0.00) \\
0 \\
(0.00)\end{array}$ & $\begin{array}{l}1 \\
(0.03) \\
5 \\
(0.17)\end{array}$ & $\begin{array}{l}1 \\
(0.03) \\
0 \\
(0.00)\end{array}$ & $\begin{array}{l}2,541 \\
(69.09) \\
1,433 \\
(48.89)\end{array}$ & $\begin{array}{l}1,022 \\
(27.79) \\
1,205 \\
(41.11)\end{array}$ & $\begin{array}{l}71 \\
(1.93) \\
209 \\
(6.89)\end{array}$ & $\begin{array}{l}3,678 \\
(100) \\
2,937 \\
(100)\end{array}$ \\
\hline $\begin{array}{l}\text { Non- } \\
\text { Korean }\end{array}$ & $\begin{array}{l}1996 \\
2008\end{array}$ & $\begin{array}{l}10 \\
(0.27) \\
40 \\
(1.36)\end{array}$ & $\begin{array}{l}184 \\
(5.00) \\
157 \\
(5.36)\end{array}$ & $\begin{array}{l}0 \\
(0.00) \\
4 \\
(0.14)\end{array}$ & $\begin{array}{l}33 \\
(0.90) \\
87 \\
(2.97)\end{array}$ & $\begin{array}{l}9 \\
(0.24) \\
23 \\
(0.78)\end{array}$ & $\begin{array}{l}1865 \\
(50.71) \\
1319 \\
(45.00)\end{array}$ & $\begin{array}{l}449 \\
(12.21) \\
315 \\
(10.75)\end{array}$ & $\begin{array}{l}1128 \\
(30.67) \\
994 \\
(33.64)\end{array}$ & $\begin{array}{l}3,678 \\
(100) \\
2,937 \\
(100)\end{array}$ \\
\hline
\end{tabular}

\subsection{Comparison of Weighted Averages of Levels of Evidence by Nationality}

Table 4 shows weighted averages of levels of evidence in Korean and non-Korean journals in 2008. Case-control studies accounted for the largest share, 40\%, of articles in Korean journals; this was followed by case studies (35\%). RCTs accounted for 5\%, cohort studies accounted for less than $2.5 \%$, and systematic reviews accounted for less than $1 \%$ of articles in Korean journals. Similarly, case-control studies accounted for the largest share of articles 
published in non-Korean journals, but research with higher levels of evidence were more common in non-Korean than in Korean journals.

Table 4. Comparison of weighted averages of levels of evidence

\begin{tabular}{l|llllllll|l}
\hline & $1 \mathrm{a}$ & $1 \mathrm{~b}$ & $2 \mathrm{a}$ & $2 \mathrm{~b}$ & $3 \mathrm{a}$ & $3 \mathrm{~b}$ & 4 & 5 & Total \\
\hline Korean & 0.08 & 1.65 & 0 & 0.20 & 0 & 41.24 & 34.49 & 9.92 & 100 \\
Non-Korean & 1.53 & 5.03 & 0.21 & 2.51 & 1.23 & 34.21 & 6.99 & 35.85 & 100 \\
\hline \hline
\end{tabular}

\subsection{Comparison of Levels of Evidence by Multiple logistic Regression}

We divided articles according to level of evidence and compared the levels of evidence in Korean and non-Korean articles. Non-Korean articles had higher levels of evidence than did Korean ones, and this difference was statistically significant. Articles published in 2008 were characterized by a significantly higher level of evidence than were those published 1996. Journals in anesthesiology showed a statistically significant higher level of evidence than did other journals (Table 5).

Table 5. Comparison of levels of Evidence for Each Clinical Area

\begin{tabular}{l|lll}
\hline \hline & Odds ratio & $95 \%$ confidence interval & $p$-value \\
\hline Nationality & & & \\
Korean & 1 & - & - \\
Non-Korean & 4.181 & $3.438-5.084$ & $<0.0001$ \\
\hline Year & & & \\
1996 & 1 & - & - \\
2008 & 1.693 & $1.433-2.001$ & $<0.0001$ \\
\hline Clinical area & & & \\
Neurosurgery & 1 & - & - \\
Internal Medicine & 6.421 & $3.178-12.973$ & $<0.0001$ \\
Pediatrics & 5.576 & $2.700-11.514$ & $<0.0001$ \\
Surgery & 5.603 & $2.703-11.614$ & $<0.0001$ \\
Obstetrics \& Gynecology & 6.998 & $3.468-14.118$ & $<0.0001$ \\
Orthopedics & 3.600 & $1.642-7.891$ & 0.0014 \\
Cardiovascular surgery & 4.337 & $2.040-9.219$ & 0.0001 \\
Ophthalmology & 6.999 & $3.482-14.067$ & $<0.0001$ \\
Otolaryngology & 2.464 & $1.136-5.344$ & 0.0224 \\
Urology & 3.804 & $1.800-8.042$ & 0.0005 \\
Psychiatry & 4.294 & $1.835-10.050$ & 0.0008 \\
Dermatology & 2.138 & $0.984-4.944$ & 0.0550 \\
Radiology & 1.775 & $0.762-4.131$ & 0.1833 \\
Anesthesiology & 17.497 & $8.845-34.612$ & $<0.0001$ \\
Family Medicine & 5.239 & $2.355-11.654$ & $<0.0001$ \\
\hline \hline
\end{tabular}




\section{Discussion}

The number of medical articles with high levels of evidence increased over the study period: the odds ratio for high levels of evidence was 1.693-fold higher in 2008 than in 1996. When the results are analyzed by nationality (Korean vs. non-Korean), however, the results changed. Even though number of RCTs doubled from 1996 to 2008 in Korean journals, large gap between Korea and oversea exist. The odds ratio for high levels of evidence was 4.181fold higher in non-Korean journals than in Korean journals. In particular, systematic reviews have been rare in Korean journals, whereas their importance has increased outside Korea. On the other hand, case studies increased, from $27.79 \%$ in 1996 to $41.11 \%$ in 2008, indicating that the level of the evidence in Korean journals has barely improved when compared with that in non-Korean journals.

Several issues should be considered in understanding why the gap in the level of evidence in non-Korean versus Korean articles has barely changed after an interval of 10 years in which the Korean medical establishment has developed rapidly. According to Jang's statistical data on Korean medical articles published in 2007, 35.7\% of articles written by Korean medical scientists were published abroad [7]. One hypothesis derived from this result is that levels of evidence in Korean and non-Korean medical articles are not, in fact, very different, but that Korean medical results are depreciated because Korean articles of high quality are actually more likely to be published in non-Korean journals. Indeed, Korean scientists tend to publish articles more frequently in overseas journals because their impact factor (in SCI) is higher than that of Korean journals. This phenomenon has been widespread in Korean academic society, including the Korean medical society, since the mid-1990s, when the performance evaluation system for university faculty based on quantitative measures of each article, especially its impact, became popular in Korea. This phenomenon is also reflected in the fact that although the number of articles in SCI journals has increased dramatically since 1997-1998, the number of articles published in Korean SCI journals remains low [8].

Our study has several limitations. The primary problem concerns the representativeness of the journals we analyzed. An ideal result would have required analysis of all articles published in a specific year, but obvious practical difficulties interfere with review of many thousands of articles. For this reason, we selected leading journals in each clinical area, which may have resulted in the exclusion of some medical articles, especially those published in basic medicine journals. A second limitation involves the scarcity of articles with high levels of evidence. Of the 13,000 articles we studied, more than two-thirds were case studies or case-control studies, whereas we reviewed far fewer RCTs and systematic reviews. In particular, the analysis of results by field typically yielded no or only one or two articles with high levels of evidence, rendering statistical comparisons among fields meaningless.

In conclusion, we were able to detect a gap in the levels of evidence contained in medical articles published in Korea and outside Korea. However, we need to further evaluate whether this gap indicates a real difference in quality between medical articles written by Korean medical researchers and those written by foreign medical researchers or whether this gap is a function of other factors, such as the tendency for high-quality articles by Korean medical researchers to be published in non-Korean journals. This evaluation will require a search of all medical articles written by Korean scientists and published in non-Korean journals and classification of these articles as "Korean." 


\section{References}

[1] R. J. Macnaughton, "Evidence and clinical judgment", Journal of Evaluation in Clinical Practice, 10.1111/j.1365-2753.1998.00002.x, vol. 4, no. 2, (1998), pp. 89-92.

[2] Evidence-Based Medicine Working Group, "Evidence-Based Medicine Working Group, A new approach to teaching the practice of medicine", Journal of the American Medical Association, 10.1001/jama.1992.03490170092032.x, vol. 268, (1992), pp. 2420-5.

[3] P. C. Wyer and S. A. Silva, "Where is the wisidom? I-A conceptual history of evidence-based medicine", Journal of Evaluation in Clinical Practice, 10.1111/j.1365-2753.2009.01323.x, vol. 15, (2009), pp. 891-898.

[4] Evidence-Based Medicine Working Group, "Users' guidelines to the medical literature. IX. A method for grading health care recommendations", Journal of the American Medical Association, 10.1001/jama.1995.03530220066035, vol. 274, (1995), pp. 1800-4.

[5] Oxford Centre for Evidence-based Medicine, "Level of Evidence", (2009), http://cebm.net/?o=1116.

[6] S. Y. Kim, "Evidence-based assessment of complementary and alternative therapies for cancer", Journal of the Korean Medical Association, 10.5124/jkma.2008.51.5.403, vol. 51, no. 5, (2008), pp. 403-410.

[7] H. R. Jang, G. W. Kang, Y. J. Tak and Y. S. Lee, "Analysis of medical articles published at home and abroad by Korean researchers in 2007", Chungbuk Medical Journal, Available at http://inst.cbnu.ac.kr/www/inst2/02.html, vol. 20, no. 1, (2010), pp. 1-10.

[8] National Academy of Medicine of Korea, Korea Medical Research Report, National Academy of Medicine of Korea Publisher, Seoul (2006). Available at http://www.namok.or.kr/bbs/index.html?code=book\&category=\&gubun=\&page=2\&number $=5 \&$ mode $=$ view \&keyfield $=\&$ key $=$.

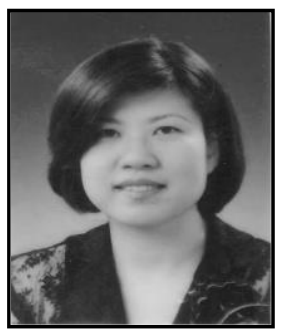

Yang Ju Tak, M.D., Ph.D., received her Ph.D. in Health Informatics \& Management from Chungbuk National University, Cheongju, Korea in 2011. Since March 2007, she has been a professor at Korea National University of Transportation, Jeungpyeong, Korea. Her current research focuses on public health management and medical informatics.

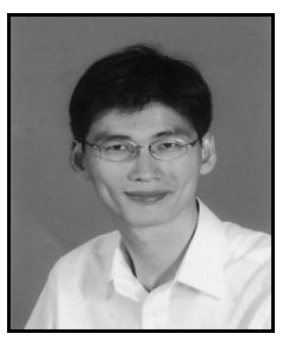

Gilwon Kang, M.D., Ph.D., received his Ph.D. in Health Policy \& Management from Seoul National University, Seoul, Korea in 1992. Since September 2006, he has been a professor at Chungbuk National University, Cheongju, Korea. His current research focuses on Health Insurance \& Patient Classification System.

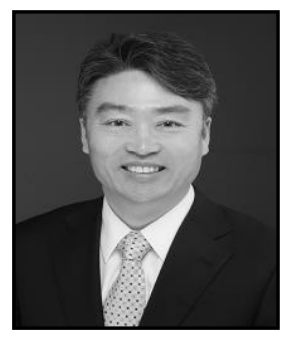

Youngsung Lee, M.D., Ph.D., has been leading MedRIC (Medical Research Information Center), focusing on research and development in medical informatics, medical data visualization, telematics, Virtual Reality-based medical training, and health communication and promotion policies and programs. Dr. Lee is Professor, College of Medicine, Chungbuk National University. He is also currently serving as a board member of the Korean Society of Medical Informatics. He was a visiting scholar at Stanford University Medical Media and Information Technology, and was a member of Committee on Infrastructure Technologies, National Science and Technology Council, the Nation's highest decision making body on science and technology policies under the President of Republic of Korea. 